\title{
GPS Receiver Position Interpretation using Single Point PVT Estimation Algorithm
}

\author{
P. Sirish Kumar, L. Ganesh, Ashok Kumar. N, V.B.S Srilatha Indira Dutt
}

\begin{abstract}
In our day-to-day lives, we need to get the correct GPS location information. GPS is based on the calculation of the pseudo-range and four unspecified parameters, but the formula is not linear in navigation observation. A single point position algorithm can solve the nonlinear equation; the algorithm is based on Taylor linearization. This paper provides an overview of the single point PVT algorithm and presents the GPS satellite pseudo-range observation equations, typically over-determined as there are only four unknown satellites, but generally, more than four are monitored and thus more than four pseudo-range observation equations. Single point PVT estimation algorithm is used to solve pseudo range observation equations in order to find position and clock bias solutions are described in detail. In this article, the position of GPS receiver is estimated w.r.t. to $\mathrm{X}, \mathrm{Y}, \mathrm{Z}$ Coordinates, in addition to that clock bias also estimated.
\end{abstract}

Keywords: clock bias, GPS, Pseudo-Range, Single point PVT.

\section{INTRODUCTION}

GPS is an all-weather navigation positioning system; it can provide three-dimensional positioning, velocity and timing services to worldwide users anywhere. To obtain location information from the GPS positioning system, we usually adopt the pseudo-range measurement method, however, the observation equation is nonlinear, and the pseudo-range equations can be linearized with Taylor's series expansion at the approximate point. So this paper studies a single point position algorithm and simulates the positioning error by true GPS data.

GPS is a weather-friendly navigation system that can offer worldwide users three-dimensional positioning, speed, and time services. We usually use the pseudo-range measurement method to obtain location information using the GPS positioning system but the observing formula is not linear; the pseudo-range formulas will linearize on the estimated point with Taylor's series expansion. This paper, therefore, studies the algorithm for single point's position and simulates the position error with true GPS data.

This paper elaborates on an efficient navigational

Revised Manuscript Received on December 13, 2019.

P. Sirish Kumar, Department of Electronics \& Communications Engineering, Aditya Institute Of Technology And Management, Tekkali,Srikakaulam, India. E-mail: sirishdg@ gmail.com

L .Ganesh, Department of Electronics \& Communications Engineering, GVP College of Engineering for Women, Visakhapatnam, India. E-mail: ganeshlaveti2010@gmail.com.

Ashok Kumar. N, Department of Electronics \& Communications Engineering, Raghu Engineering College(A), Dakamarri, Visakhapatnam, India. E-mail:ashok0709@gmail.com

V B S Srilatha Indira Dutt, Department of Electronics \& Communications Engineering, GIT, GITAM, Visakhapatnam, India. E-mail: srilatha06.vemuri@gmail.com. algorithm over IISc, Bangalore (South Zone of Indian Subcontinent) data to increase the efficiency of the GPS receiver position estimation.

\section{SINGLE POINT-PVT ESTIMATION ALGORITHM}

Fundamental equations will be presented to calculate the user position. Suppose the calculated range is correct and three satellites probably be sufficient under this condition.

$$
\begin{aligned}
& S_{r 1}=\sqrt{\left(p_{1}-p_{u}\right)^{2}+\left(q_{1}-q_{u}\right)^{2}+\left(r_{1}-r_{u}\right)^{2}} \\
& S_{r 2}=\sqrt{\left(p_{2}-p_{u}\right)^{2}+\left(q_{2}-q_{u}\right)^{2}+\left(r_{2}-r_{u}\right)^{2}} \\
& S_{r 3}=\sqrt{\left(p_{3}-p_{u}\right)^{2}+\left(q_{3}-q_{u}\right)^{2}+\left(r_{3}-r_{u}\right)^{2}}
\end{aligned}
$$

Where, $\left(\mathrm{p}_{1}, \mathrm{p}_{2}, \mathrm{p}_{3}\right),\left(\mathrm{q}_{1}, \mathrm{q}_{2}, \mathrm{q}_{3}\right),\left(\mathrm{r}_{1}, \mathrm{r}_{2}, \mathrm{r}_{3}\right)$ are known locations, $\left(\mathrm{p}_{\mathrm{u}}, \mathrm{q}_{\mathrm{u}}, \mathrm{r}_{\mathrm{u}}\right)$ are unknown locations and $\mathrm{S}_{\mathrm{r} 1}, \mathrm{~S}_{\mathrm{r} 2}$ and $\mathrm{S}_{\mathrm{r} 3}$ are the pseudo ranges of the three satellites respectively. Since three unknowns and three equations exist, from these equations $\mathrm{p}_{\mathrm{u}}, \mathrm{q}_{\mathrm{u}}, \mathrm{r}_{\mathrm{u}}$ values can be obtained. Solutions of two sets, since they are equations of order 2, should be theoretically available. Because these equations are not linear, they are hard to solve. But linearization and an iterative approach can solve these equations easily.

\section{A. MEASUREMENT OF PSEUDO-RANGE:}

The time of the satellite clock $\left(t^{\prime}\right.$ sat $)$ and the current time of the user clock ( $\left.t^{\prime} r x\right)$ are related to the estimated time of the satellite is given by

$$
\begin{gathered}
\mathbf{t}_{\mathrm{sat}}^{\prime}=\mathbf{t}_{\mathrm{sat}}+\Delta \mathrm{t} \\
\mathbf{t}^{\prime}{ }_{\mathrm{rx}}=\mathbf{t}_{\mathrm{rx}}+\Delta \mathrm{T}
\end{gathered}
$$

Where $\Delta \mathrm{t}=$ Satellite clock offset

$\Delta \mathrm{T}=$ Receiver clock offset

The pseudo range $\mathrm{Sr}$ will therefore be evaluated as an equation

$$
\mathrm{S}_{\mathrm{R}}=\mathrm{S}_{\mathrm{r}}+\mathrm{c}(\Delta \mathrm{t}-\Delta \mathrm{T})+\Delta_{\text {ion }}+\Delta_{\text {trop }}+\mathrm{M}
$$

Here

$\mathrm{S}_{\mathrm{R}}=$ Measured Pseudo Range

$\mathrm{S}_{\mathrm{r}}=$ True Range

$\Delta \mathrm{t}=$ Receiver Clock Offset

$\Delta \mathrm{T}=$ Satellite Clock Offset

$\Delta_{\text {ion }}=$ Ionospheric Error

$\Delta_{\text {trop }}=$ Tropospheric Error

M= Multipath Error

The errors cause the user's location to be inaccurate. The clock bias cannot so that it will 
also remain unknown.

Assume ( $\mathrm{p} \mathrm{q}$ r) be the position of the satellite and $\left(\mathrm{p}_{\mathrm{u}} \mathrm{q}_{\mathrm{u}} \mathrm{r}_{\mathrm{u}}\right)$ be the position of the receiver, then replace the geometrical range $c\left(t_{r x}-t_{s a} t\right)$, that is $S_{r}$ as

$$
\begin{aligned}
& \mathbf{c}\left(\mathbf{t}_{\mathrm{rx}}-\mathbf{t}_{\mathrm{sat}}\right)=\mathbf{S}_{\mathbf{r}}= \\
& c\left(t_{u}-t_{s v}\right)=\mathbf{S}_{\mathbf{r}}=\sqrt{\left(\mathbf{p}-\mathbf{p}_{\mathbf{u}}\right)^{2}+\left(\mathbf{q}-\mathbf{q}_{\mathbf{u}}\right)^{2}+\left(\mathbf{r}-\mathbf{r}_{\mathbf{u}}\right)^{2}}
\end{aligned}
$$

As a consequence Eqn. (4) can be further modified as

$$
\begin{aligned}
& S_{R}=\sqrt{\left(p-p_{u}\right)^{2}+\left(q-q_{u}\right)^{2}+\left(r-r_{u}\right)^{2}}+d_{u}+c \cdot \Delta t+\Delta_{\text {ion }} \\
& +\Delta_{\text {trop }}+\mathrm{M}
\end{aligned}
$$

Where $\mathrm{d}_{u}$ is user clock bias

The other error variables were overlooked for convenience except the receiver clock bias. The Eqn. (6) can be expressed as

$$
S_{R}=\sqrt{\left(p-p_{u}\right)^{2}+\left(q-q_{u}\right)^{2}+\left(r-r_{u}\right)^{2}}+d_{u}
$$

Since the Eqn. (6) includes four unknowns. Four such satellite range equations are essential for solving four distinct satellites.

$$
\begin{aligned}
& S_{R 1}=\sqrt{\left(p_{1}-p_{u}\right)^{2}+\left(q_{1}-q_{u}\right)^{2}+\left(r_{1}-r_{u}\right)^{2}}+d_{u} \\
& S_{R 2}=\sqrt{\left(p_{2}-p_{u}\right)^{2}+\left(q_{2}-q_{u}\right)^{2}+\left(r_{2}-r_{u}\right)^{2}}+d_{u} \\
& S_{R 3}=\sqrt{\left(p_{3}-p_{u}\right)^{2}+\left(q_{3}-q_{u}\right)^{2}+\left(r_{3}-r_{u}\right)^{2}}+d_{u} \\
& S_{R 4}=\sqrt{\left(p_{4}-p_{u}\right)^{2}+\left(q_{4}-q_{u}\right)^{2}+\left(r_{4}-r_{u}\right)^{2}}+d_{u}
\end{aligned}
$$

Four unknown equations $\mathrm{P}_{\mathrm{u}}, \mathrm{Q}_{\mathrm{u}}, \mathrm{R}_{\mathrm{u}}$, and $\mathrm{d}_{\mathrm{u}}$ must solve in Eq uation (7). Therefore, at least four satellites for the user locat ion should be solved on a GPS receiver.

\section{SOLUTION OF USER POSITION FROM PSEUDORANGES}

The four unknowns in Eqn. (7) are difficult to resolve. Because the simultaneous equations are nonlinear. Linearizing them is a growing way of resolving the issue. The equations described above can be written in a simplified way

$$
S_{r i}=\sqrt{\left(p_{i}-p_{u}\right)^{2}+\left(q_{i}-q_{u}\right)^{2}+\left(r_{i}-r_{u}\right)^{2}}+d
$$

Where $\mathrm{i}=1$ to 4 ,

$\mathrm{p}_{i}, \mathrm{q}_{i}, \mathrm{r}_{i}=$ satellite positions,

$\mathrm{Sr}_{\mathrm{i}}=$ pseudo range

By differentiating the equation (8), we can get

$$
\delta S_{r i}=\frac{\left(p_{i}-p_{u}\right) \delta p_{u}+\left(q_{i}-q_{u}\right) \delta q_{u}+\left(r_{i}-r_{u}\right) \delta r_{u}}{\sqrt{\left(p_{i}-p_{u}\right)^{2}+\left(q_{i}-q_{u}\right)^{2}+\left(r_{i}-r_{u}\right)^{2}}}+\delta d_{u}
$$

$\mathrm{p}_{u}, \mathrm{q}_{u}, \mathrm{r}_{u}, \mathrm{~d}_{u}=$ unknowns,

$=\frac{\left(p_{i}-p_{u}\right) \delta p_{u}+\left(q_{i}-q_{u}\right) \delta q_{u}+\left(r_{i}-r_{u}\right) \delta r_{u}}{S_{r i}-d_{u}}+\delta d_{u}$

The only unknown in this formula were $\delta \mathrm{p}_{u}, \delta \mathrm{q}_{u}, \delta \mathrm{r}_{u}$, and $\delta \mathrm{d}_{u}$. The values $\mathrm{p}_{u}, \mathrm{q}_{u}, \mathrm{r}_{u}$, and $\mathrm{d}_{u}$

are considered as identified values because for these values one can predict certain initial values

The above formula becomes a set of linear equations with $\delta \mathrm{p}_{\mathrm{u}}$, $\delta \mathrm{q}_{\mathrm{u}}, \delta \mathrm{r}_{\mathrm{u}}$, and $\delta \mathrm{d}_{\mathrm{u}}$ as unknown. Often this procedure is called linearization. The equation above can be written as a matrix

$$
\left[\begin{array}{l}
\delta S_{r 1} \\
\delta S_{r 2} \\
\delta S_{r 3} \\
\delta S_{r 4}
\end{array}\right]=\left[\begin{array}{llll}
A_{11} & A_{12} & A_{13} & 1 \\
A_{21} & A_{22} & A_{23} & 1 \\
A_{31} & A_{32} & A_{33} & 1 \\
A_{41} & A_{42} & A_{43} & 1
\end{array}\right]\left[\begin{array}{l}
\delta p_{u} \\
\delta q_{u} \\
\delta r_{u} \\
\delta d_{u}
\end{array}\right]
$$

where

$$
\begin{aligned}
& A_{i 1}=\frac{p_{i}-p_{u}}{S_{r i}-d_{u}} \\
& A_{i 2}=\frac{q_{i}-q_{u}}{S_{r i}-d_{u}} \\
& A_{i 3}=\frac{r_{i}-r_{u}}{S_{r i}-d_{u}}
\end{aligned}
$$

The solution of Equation (10) is

$$
\left[\begin{array}{l}
\delta p_{u} \\
\delta q_{u} \\
\delta r_{u} \\
\delta d_{u}
\end{array}\right]=\left[\begin{array}{llll}
A_{11} & A_{12} & A_{13} & 1 \\
A_{21} & A_{22} & A_{23} & 1 \\
A_{31} & A_{32} & A_{33} & 1 \\
A_{41} & A_{42} & A_{43} & 1
\end{array}\right]^{-1}\left[\begin{array}{l}
\delta S_{r 1} \\
\delta S_{r 2} \\
\delta S_{r 3} \\
\delta S_{r 4}
\end{array}\right]
$$

Where, the A is inverse matrix. Clearly, this equation does not directly give the necessary solutions, but it is possible to obtain the desired solutions. This formula needs to be used iteratively repeatedly to find the optimal position solution. A quantity is typically used to evaluate the desired result and can be defined as

$$
\delta \Gamma=\sqrt{\delta \mathbf{p}_{u}^{2}+\delta \mathbf{q}_{u}^{2}+\delta \mathbf{r}_{u}^{2}+\delta \mathbf{d}_{u}^{2}}
$$

If the value is < defined threshold, then the iteration stops.

\section{POSITION SOLUTION USING MORE THAN FOUR SATELLITES}

If more than 4 satellite vehicles are available, it is more popular to use all satellites to resolve the user's position. Similarly, the position solution can be found. If $\mathrm{n}$ satellites exist, Eqn. (8) can be written as:

$$
S_{r i}=\sqrt{\left(p_{i}-p_{u}\right)^{2}+\left(q_{i}-q_{u}\right)^{2}+\left(r_{i}-r_{u}\right)^{2}}+d_{u}
$$

Where $\mathrm{i}=1$ to $\mathrm{n}$

By linearizing the equation (14) we can get the solution 


$$
\left[\begin{array}{c}
\delta S_{r 1} \\
\delta S_{r 2} \\
\delta S_{r 3} \\
\delta S_{r 4} \\
\vdots \\
\delta S_{r n}
\end{array}\right]=\left[\begin{array}{rrrr}
A_{11} & A_{12} & A_{13} & 1 \\
A_{21} & A_{22} & A_{23} & 1 \\
A_{31} & A_{32} & A_{33} & 1 \\
A_{41} & A_{42} & A_{43} & 1 \\
& \vdots & & \\
A_{n 1} & A_{n 2} & A_{n 3} & 1
\end{array}\right]\left[\begin{array}{c}
\delta p_{u} \\
\delta q_{u} \\
\delta r_{u} \\
\delta d_{u}
\end{array}\right]
$$

Where

$$
\begin{aligned}
& A_{i 1}=\frac{p_{i}-p_{u}}{S_{r i}-d_{u}} \\
& A_{i 2}=\frac{q_{i}-q_{u}}{S_{r i}-d_{u}} \\
& A_{i 3}=\frac{r_{i}-r_{u}}{S_{r i}-d_{u}}
\end{aligned}
$$

Equation (16) can be written in simplified form as

$$
\delta S_{\mathrm{ri}}=\mathrm{A} \delta \mathrm{P}
$$

Where $\delta \mathrm{S}_{\mathrm{ri}}$ and $\delta \mathrm{P}$ are vectors, $\mathrm{A}$ is a matrix.

They can be written as

$$
\begin{aligned}
\delta S_{\mathrm{ri}} & =\left[\begin{array}{lll}
\delta \mathrm{S}_{\mathrm{r} 1} & \delta \mathrm{S}_{\mathrm{r} 2} \cdots & \boldsymbol{\delta} \mathrm{S}_{\mathrm{rn}}
\end{array}\right]^{\mathrm{T}} \\
\delta P & =\left[\begin{array}{llll}
\delta \mathrm{p}_{\mathrm{u}} & \delta q_{\mathrm{u}} & \delta \mathrm{r}_{\mathrm{u}} & \delta \mathrm{d}_{\mathrm{u}}
\end{array}\right]^{\mathrm{T}} \\
\mathrm{A} & =\left[\begin{array}{rrrr}
\mathrm{A}_{11} & \mathrm{~A}_{12} & \mathrm{~A}_{13} & 1 \\
\mathrm{~A}_{21} & A_{22} & A_{23} & 1 \\
A_{31} & A_{32} & A_{33} & 1 \\
A_{41} & A_{42} & A_{43} & 1 \\
& \vdots & & \\
A_{n 1} & A_{n 2} & A_{n 3} & 1
\end{array}\right]
\end{aligned}
$$

It cannot be reversed explicitly, as it is not a square matrix. Equation (17) remains an equation of linearity. If a set of linear equations have more equations than unknowns, single point PVT algorithm will be used to find solutions. To achieve the required solution, the pseudo inverse of $\mathrm{A}$ can be used. The response is:

$$
\delta \mathbf{P}=\left[A^{T} A\right]^{-1 \mathrm{~A} T} \delta \mathbf{S}_{\mathbf{r i}}
$$

Eqn. (18), the $\delta p_{u}, \delta q_{u}, \delta r_{u}$, and $\delta d_{u}$ values are available. The single point PVT method typically provides a better result than the location calculated from just four satellites as more information is being used.

\section{RESULT AND DISCUSSION}

In this paper, single point PVT algorithm was introduced and evaluated with the 9 hour batch processing GPS data consisting of various multi-epoch satellites positions collected from IISc, Bangalore (Latitude 13.0210 North, Longitude 77.50 East) to analyze the positional errors of $x, y, z$ coordinates and clock bias of the GPS receiver using single point PVT algorithm, which is shown in table 1 , figure $1 \& 2$ respectively. Table 2 and Table 3 show the maximum and minimum values of coordinate errors, mean values, and statistical error measures respectively.

In addition to that in this paper, the Gaussian distribution curved plots of SP-PVT concerning $\mathrm{x}, \mathrm{y}, \mathrm{z}-$ axis are shown in figures $3,4, \& 5$. It can be observed from the plots represented in fig. $4,5 \& 6$, the Gaussian appropriation, (otherwise called the Normal dissemination) is likelihood dispersion. Its chime molded bend is reliant on $\mu$, the mean, and $\sigma$, the standard deviation ( $\sigma$ 2being the difference). The pinnacle of the diagram is constantly situated at the mean and the zone under the bend is in every case precisely equivalent to $1.68 \%$ of the considerable number of qualities exist in one standard deviation of the mean. At $2 \sigma$, this increments to $95 \%$, and $99.7 \%$ of the qualities exist in $3 \sigma$ of the mean. Figure 6 shows the scatter plot which is used to represent the relationship between $\mathrm{x}, \mathrm{y}$ coordinate errors respectively.

Table 2: Maxima, Minima and Mean errors of X,Y,Z coordinates

\begin{tabular}{|c|c|c|}
\hline \multicolumn{2}{|c|}{ Parameter } & $\begin{array}{c}\text { Single Point- } \\
\text { PVT method }\end{array}$ \\
\hline \multirow{2}{*}{ X-Coordinate error } & Max & $64.47 \mathrm{mts}$ \\
\cline { 2 - 3 } & Min & $19.52 \mathrm{mts}$ \\
\hline \multirow{2}{*}{ Y-Coordinate error } & Max & $78.64 \mathrm{mts}$ \\
\cline { 2 - 3 } & Min & $0.10 \mathrm{mts}$ \\
\hline \multirow{2}{*}{ Z-Coordinate error } & Max & $40.97 \mathrm{mts}$ \\
\cline { 2 - 3 } & Min & $0.00068 \mathrm{mts}$ \\
\hline \multirow{3}{*}{ Mean } & X & 33.39 \\
\cline { 2 - 3 } & Y & 30.09 \\
\cline { 2 - 3 } Standard Deviation & $\mathrm{Z}$ & 6.78 \\
\cline { 2 - 3 } & $\mathrm{X}$ & 7.29 \\
\cline { 2 - 3 } & $\mathrm{Y}$ & 19.88 \\
\hline
\end{tabular}

Table 3: Statistical measures

\begin{tabular}{|c|c|}
\hline Parameter & Value(mts) \\
\hline CEP & 16.41 \\
\hline SEP & 17.15 \\
\hline MRSE & 22.13 \\
\hline DRMS & 21.17 \\
\hline 2DRMS & 42.35 \\
\hline
\end{tabular}


GPS Receiver Position Interpretation using Single Point PVT Estimation Algorithm

Table 1: X, Y, Z coordinate Position Error over 10 Epochs for SP-PVT Algorithm

\begin{tabular}{|c|c|c|c|c|}
\hline EPOCH & X-ERROR(mts) & Y-ERROR $(\mathrm{mts})$ & Z-ERROR(mts) & Clock bias(ns) \\
\hline 7200 & 26.53429 & 27.3165 & 4.70862 & 21.3 \\
\hline 7230 & 25.36842 & 26.8658 & 4.64071 & 21.0 \\
\hline 7260 & 25.57751 & 25.7504 & 3.36721 & 16.9 \\
\hline 7290 & 26.97694 & 26.2266 & 4.53596 & 17.0 \\
\hline 7320 & 25.50503 & 27.1863 & 4.75564 & 21.9 \\
\hline 7350 & 25.87386 & 27.4313 & 4.66238 & 22.3 \\
\hline 7380 & 26.69115 & 26.5675 & 3.97094 & 18.6 \\
\hline 7410 & 26.40537 & 27.40725 & 4.92134 & 21.8 \\
\hline 7440 & 26.32731 & 25.96074 & 4.38827 & 18.2 \\
\hline 7470 & 26.52837 & 26.27045 & 4.58222 & 18.3 \\
\hline
\end{tabular}

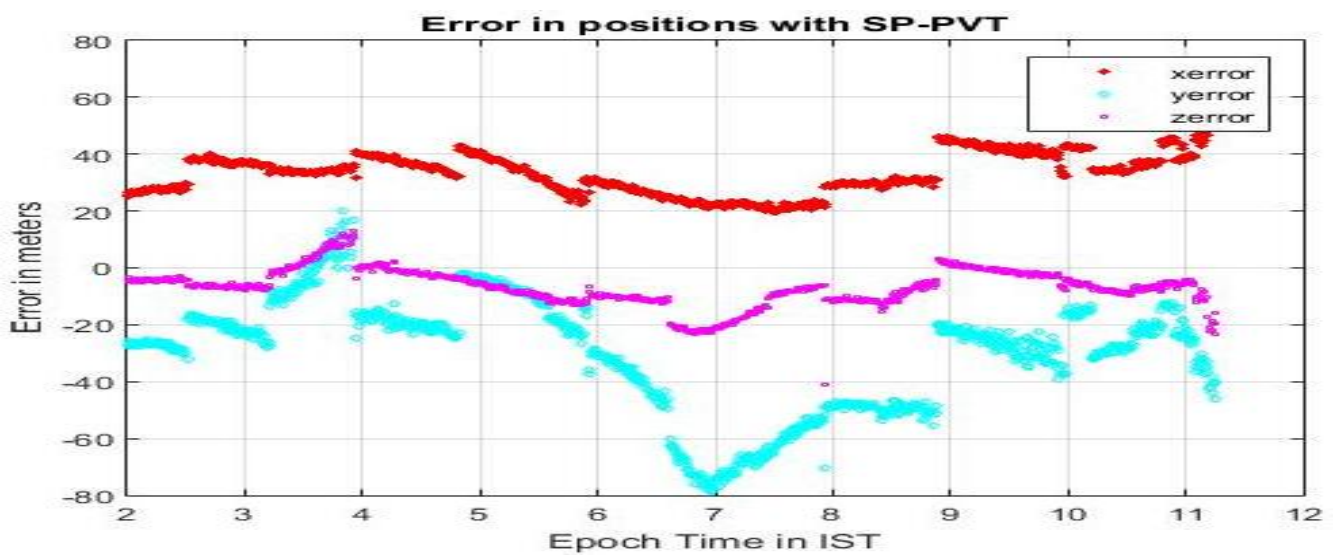

Fig 1: X, Y, Z Coordinate errors logged for 9 hrs (IISC, Bangalore) with SP-PVT

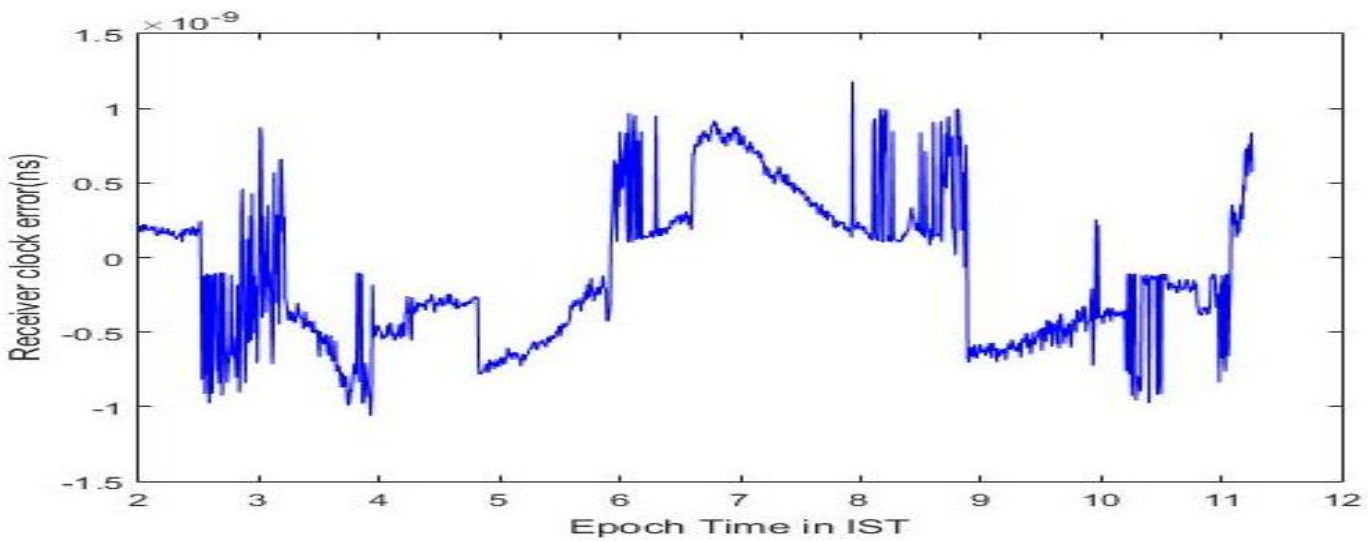

Fig 2: Receiver Clock error

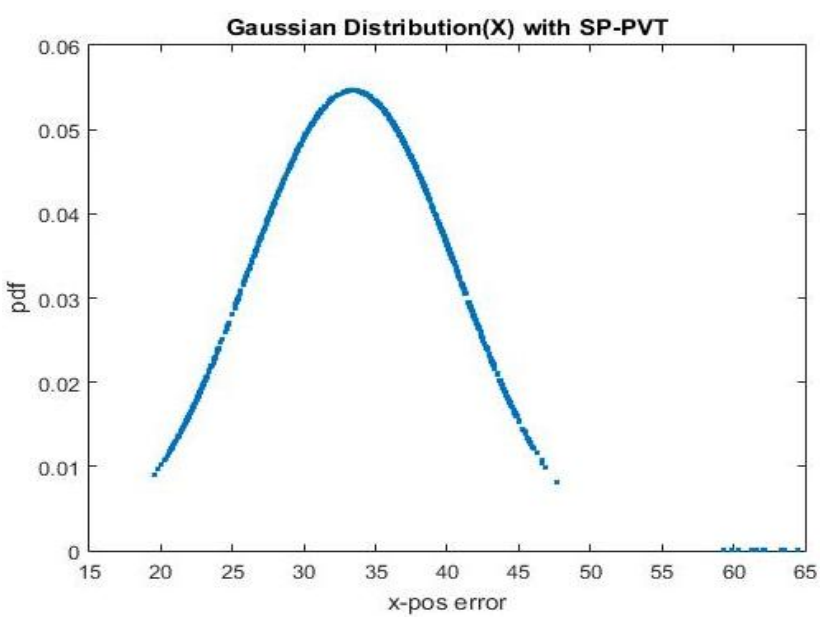

Fig 3:Gaussian Distirbution w.r.t $X$-axis with SP-PVT

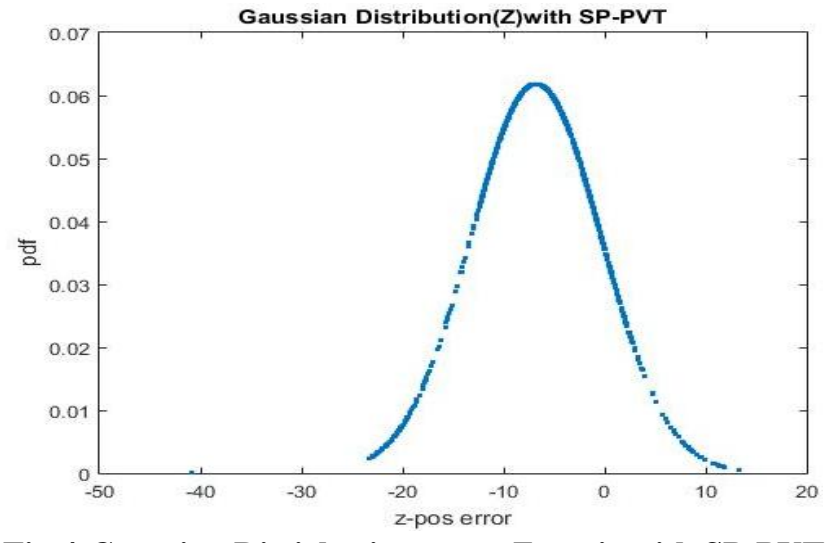

Fig 4:Gaussian Distirbution w.r.t $Z$-axis with SP-PVT

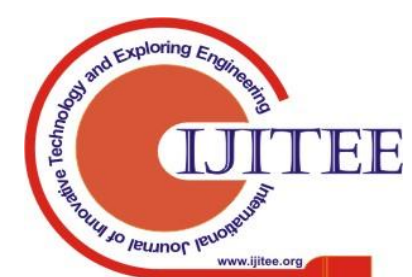




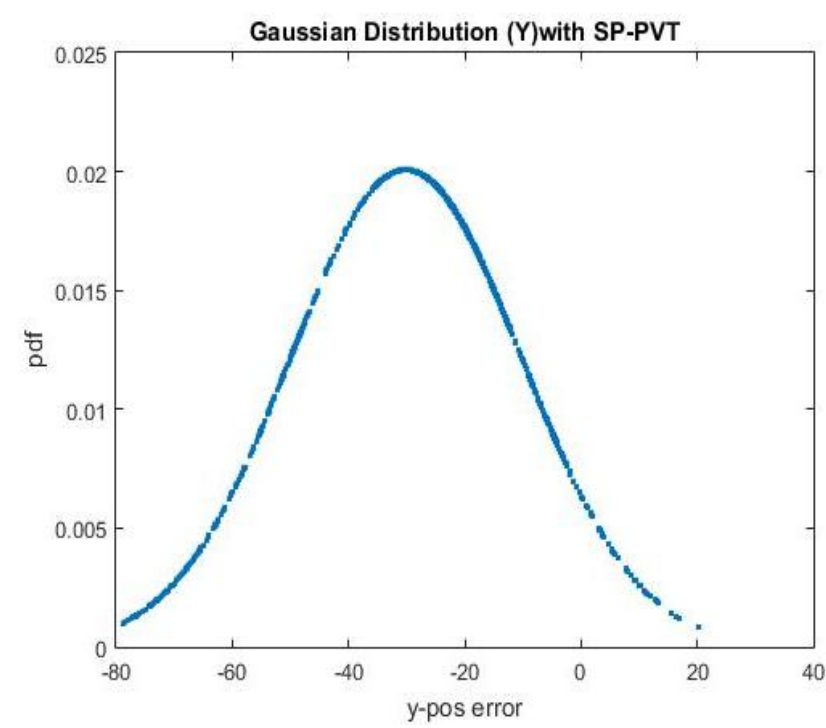

Fig 5:Gaussian Distirbution w.r.t $Y$-axis with SP-PVT

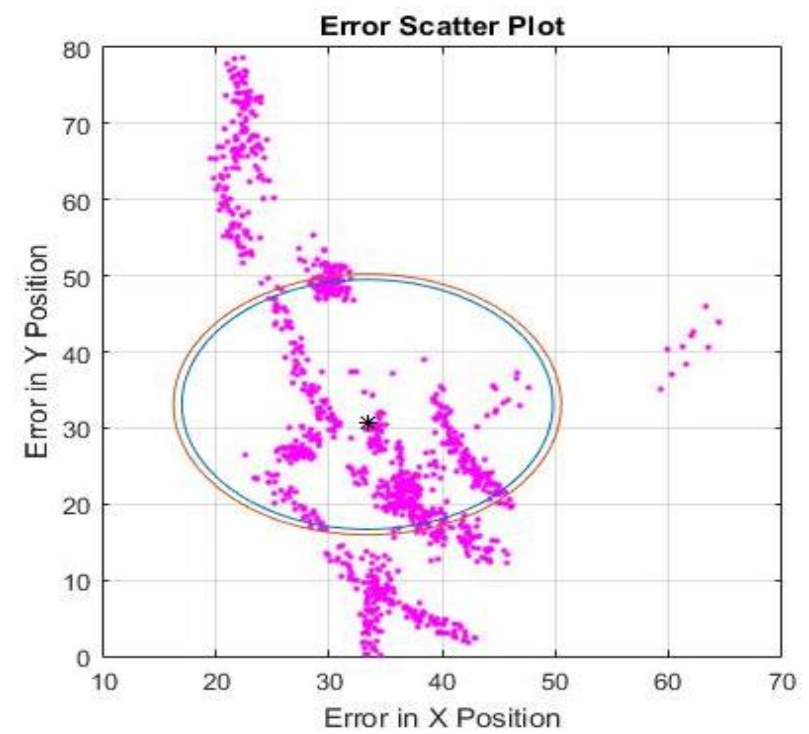

Fig 6: Scatter plot with SP-PVT

\section{CONCLUSION}

The emphasis of this paper is on introducing a precise navigational solution across the southern Indian sub-continent, therefore the SP-PVT algorithm is evaluating the GPS receiver data from Bangalore IISC (13.0210N/77.50E). By examining this method, we can conclude that the estimated positions are near close to the original receiver position. And also CEP and SEP values are $16.41 \mathrm{mts}, 17.15 \mathrm{mts}$. That means $50 \%$ of the horizontal and vertical errors are within the limits of 16.41 and 17.15 respectively.

Single point PVT thus reliably assesses the GPS receiver locations, as well as offers, enhanced possibilities in research areas such as geodesy (GPS seismology, etc.) for non-linear estimation of problems.

\section{REFERENCES}

1. Xiaojing Du, Li Liu, Huaijian Li, "Experimental Study on GPS Non-linear Least Squares Positioning Algorithm”, 2010 International Conference on Intelligent Computation Technology and Automation.

2. G.S.Rao "Global Navigation Satellite Systems" $11^{\text {st }}$ edition, India, Tata Mc-Graw Hill 2010.
3. Li Liu et al., "Experimental Study on GPS Non-linear Least Squares Positioning Algorithm", ICICTA, IEEE CS, 2010.

4. Novatel,"GPS Position Accuracy Measures”, APN-029 Rev 1,December 2003

5. Brian J.Odelson, Murali R.Rajamani and James B. Rawlings, "A New Auto covariance Least-Squares Method for Estimating Noise Covariances", Texas-Wisconsin Modeling and Control Consortium (TWMCC), Technical report number 2003-04.

6. P. Sirish Kumar, V.B.S. Srilatha Indira Dutt," Evaluation of GPS Receiver Position Accuracy Improvement Using Least Squares Estimator over the South Zone of Indian Subcontinent", Jour of Adv Research in Dynamical \& Control Systems, Vol. 11, No. 6, 2019.

\section{AUTHORS PROFILE}

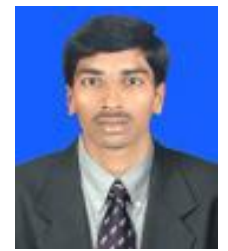

P.Sirish Kumar received M.Tech degree in VLSI System Design from Aditya Institute of Technology and Management, Tekkali, Srikakulam. He is currently working as an Assistant Professor in Aditya Institute of Technology and Management, Tekkali, Srikakulam. He is currently doing $\mathrm{Ph}$. D. from GITAM University, Visakhapatnam. His research interests are global positioning system and embedded systems. He has 20 publications in various national, international Journals.

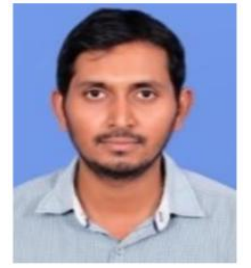

Dr. L.Ganesh is currently working as an Associate Professor with Dept of ECE, GVP College of Engineering for Women, Visakhapatnam. He completed his B.Tech from Pydah College of Engineering, Visakhapatnam and M.Tech from Chaitanya College of Engineering; Visakhapatnam $\mathrm{He}$ also completed his Ph.D from AU college of Engineering, Visakhapatnam with GPS as research area. He has more than 50 publications in various national, international conferences and Journals.

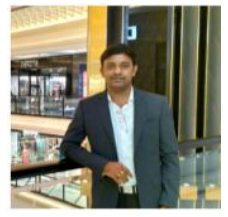

Dr. N.Ashok kumar is currently working as an Associate Professor with Dept of ECE, Raghu Engineering College(A), Visakhapatnam. $\mathrm{He}$ completed his M.Tech from AU College of Engineering, Visakhapatnam. He also completed his Ph.D from Andhra University college of Engineering,Vishakhapatnam with GPS as research area .He has more than 25 publications in various national, international conferences and Journals.

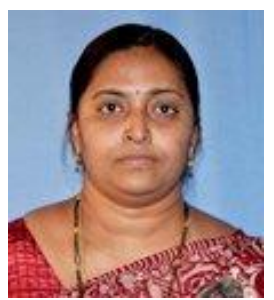

Dr.V.B.S.Srilatha Indira Dutt is currently working as a Professor \& Asst. Principal with Dep of ECE, GITAM University, Visakhapatnam. She completed her B.Tech from VR Siddartha engineering college and M.Tech from Andhra University college of Engineering,Vishakhapatnam. She also completed her Ph.D from Andhra University college of Engineering,Vishakhapatnam with GPS as research area. She is a Life member of IETE. She has more than 70 publications in various national, international conferences and Journals. 